\title{
A PÓS-VERDADE E A GUARDA DO REBANHO ${ }^{1}$
}

\section{POST TRUTH AND TENDING THE FLOCK}

\author{
Carlos Fortuna \\ Centro de Estudos Sociais e Faculdade de Economia da Universidade de Coimbra, Praça Dom Dinis, \\ 3000-104 Coimbra. Email: cfortuna@fe.uc.pt
}

\begin{abstract}
Resumo: Viver na era da pós-verdade é enfrentar uma inusitada situação de realidades e relatos fractais que mistura factos, verdades e mentiras e onde tudo surge distorcido. Para a Sociologia, o desafio é enorme e aconselha mesmo a des-aprender muito do que antes eram convicções fortes sobre como investigar. Quando tudo parecia estar a tornar-se cada vez mais acessível e aberto, eis-nos perante um fechamento neo-tribal em redes e redes de redes que tudo dizem e desdizem com intrépida velocidade. $\mathrm{O}$ capitalismo que hoje é (também) do conhecimento a tua fast e soft sobre os modos de perceber a sociedade, o mercado e o poder. Usa em seu favor centros e laboratórios, sujeita os CVs a métricas sinistras e faz projetar em bodes expiatórios a explicação dos fracassos e dos desligamentos do mundo. A Sociologia tem de se re-fazer e mobilizar todos os sentidos para dar conta, como o poeta, como o rebanho está a ser guardado.
\end{abstract}

Palavras-chave: pós-verdade, redes sociais, Sociologia, capitalismo do conhecimento.

\begin{abstract}
To live in the post-truth era is to face unusual realities and fractal reports in which facts, truths and lies are merged and everything appears distorted. For Sociology, this is an enormous challenge that advises us to un-learn much of our once strong convictions about how to research. When everything seemed to be increasingly more accessible and open, we are faced up against a neo-tribal closure in networks and networks of networks that say and unsay everything with intrepid speed. Capitalism, that today is (also) knowledge capitalism, acts fast and soft on the ways of perceiving society, the market and power. It uses research centres and laboratories on its behalf, subjects CVs to sinister metrics, and renders the explanation of its failures and world's disconnections to become scapegoats. Sociology has to re-do itself and mobilize all senses to account, as the poet, how the flock is being tended.
\end{abstract}

Keywords: post-truth, social networks, sociology, knowledge capitalism.

De repente, perante o desafio do X Congresso Português de Sociologia subordinado ao tema "Na era da 'pós-verdade'? Esfera pública, cidadania e qualidade da democracia no Portugal contemporâneo", dei comigo a pensar sobre o pouco que sei do que é a pós-verdade. Verdade mesmo! Dos factos sociológicos, julgo saber alguma coisa e da mentira, de novo, é mínimo aquilo o que posso dizer. Permito-me afirmar que uns e outras - factos, verdades, mentiras - ajudam a desenhar a realidade à sua maneira ... e que, a cada instante, esta se reconfigura, altera, aumenta, torna-se difusa, impercetível, indefinida, distorcida e, por fim, não se deixa ler, exatamente como a identidade do "homem da multidão", glosado por Alan Poe. O que parece ser, afinal, não é. E assim vamos vivendo com esta "sociológica incredulidade", tanto cognitiva como política, resultante de misturas de factos, 
verdades e mentiras, com retalhos de uns e de outras que os media e as redes sociais fornecem a cada hora. Hoje, vemos, ouvimos e lemos, como se fazia antes, coisas que se não são verdade, parecem sê-lo e com as quais queremos tornar o mundo sociologicamente inteligível e autêntico, mesmo se estranho. Coisas com que pensamos que poder ir mais a fundo no entendimento da condição humana.

A Sociologia do século XX ensinou-me a pensar sobre o que são realmente a sociedade, o mercado e o poder, quando os vemos? Essa era o inquietante questionamento que surgia em cada seminário de doutoramento de Immanuel Wallerstein, nos idos anos 1980s. E, munido de tal pergunta, partia a caminho da "verdade" dos factos. Uma verdade que a história e os arquivos mantinham por revelar... E que as conversas programadas com outros - chamadas entrevistas - podiam testemunhar. Uma verdade retida nos relatos jornalísticos, nos microfilmes dos principais jornais do globo de então e, porque não dizê-lo, também nos livros de sociologia e outros que então se liam sofregamente.

Diz-se agora que nada mais continua a ser assim. Hoje, as verdades são todas relativas em excesso e parciais (Kakutani, 2018), pelo que no dizer de Saramago, o tempo das verdades plurais acabou e hoje o que temos é um tempo de mentira universal. Será verdade? Pouco literária e mais sociologicamente, aponta-se o dedo ao ciberespaço, às redes (nets) e às redes de redes (internets) e ao discurso das tribos que cada um/a acolhe. Hello Mr. Facebook! A abertura ao mundo e ao conhecimento, afinal, revela-se falsa e torna-se mesmo "fechamento", como assegura o nosso colega João Teixeira Lopes (2018). Fechamento naquilo que queremos ouvir e, que distraidamente, adoça o poderoso efeito de subordinação planetária a juízos, preconceitos, tecnologias, invenções e manipulações da realidade e, acima de tudo, manipulação contínua da nossa própria condição. Talvez ilegítima, mas consentida, como é a planetariedade de Gayatri Spivak (2003), que sugere sermos nós e a nossa alteridade que se produzem ao mesmo tempo através desse ambíguo "fechamento" neo-tribal.

Apontar o dedo a "pseudo jornalistas", à iliteracia digital e a outros inoportunos responsáveis por esta paradoxal condição de estarmos isolados em rede não basta. Gostaria de poder continuar a fazer a boa Sociologia do século XX e a deixar-me inquietar com a busca de como e de quê são feitos a sociedade, o mercado e o poder quando os confrontamos.

Gostaria, por isso, de resgatar aquilo que Ivan Illich chamou de "contraprodutividade". No fundo não passa da autonomia dos meios face aos fins, ou se quisermos, do uso excessivo de determinado dispositivo mecânico, ou argumentativo, que acaba por se afastar inelutavelmente dos propósitos para que fora instituído. Ivan Illich criticava a contraprodutividade do sistema escolar que deixou de 
ser apenas escola e capacidade de ensinar e de aprender, para se tornar legítimo lutar por "des-escolarizar" as sociedades. De igual modo, e por iguais motivos, criticou também o sistema de saúde, que era para ser apenas capacidade de curar e de viver uma vida saudável. Eu gostaria aqui de usar a contraprodutividade illitchiana para criticar o atual sistema de comunicação que, a meu ver, era para ser apenas capacidade de informar e de nos fazer interagir e viver uma vida digna e está, paradoxalmente, a tornar muito difícil fazê-lo.

A moderna comunicação assenta hoje na intensidade e na velocidade da produção da informação. Reside também no facto de não termos de procurar esta informação (adeus arquivos e registos do século passado...). Ela vem ter diretamente connosco. Na atual cultura do aceleracionismo, a intensidade, a velocidade e a pronta disponibilidade da informação, juntas, resultam no seu pérfido e contraprodutivo "excesso" informativo.

Intensidade, rapidez e acesso fácil à informação sobre todos os domínios da vida são também as bases do novo capitalismo do conhecimento (a expressão é de Nigel Thrift, 2005). Trata-se de uma versão soft do capitalismo que está, insidiosamente, a alterar as práticas académicas mais rotineiras com que, vindas do velho século XX, todos/as tínhamos sido ensinados/as.

Este capitalismo do conhecimento está a obrigar-nos a ir, desenfreadamente, em busca de projetos financiados, de parcerias, de bolsas e de revistas com fator de impacto. Este novo capitalismo está a tornar-se mais e mais inteligente e sofisticado e usa e abusa, como nunca, da capacidade reflexiva, da inteligência, da educação económica e financeira, do conhecimento e da cultural empresarial. Será aqui que radica a pós-verdade? É já sem surpresa que assistimos diariamente à erosão das fronteiras entre "academia" e "negócio". Na cultura do aceleracionismo, a academia responde ao jeito do clickbait e da quick response académica. Interessa-se mais pela resposta e a informação do que pela pergunta. Perguntar parece coisa do passado. Com frequência, as Teses de Doutoramento relatam, descrevem e informam mais do que questionam e problematizam. E disso se alimentam as universidadese os seus pensadores repentistas. São os fast thinkers académicos que comentam, por "dá cá aquela palha", aspetos mais ou menos superficiais da vida social ou aquilo que provoca curiosidade pública, se não mesmo entretenimento, sem se darem conta, tantos deles, do nexo negativo entre "urgência" e "pensamento", que Bourdieu assinalou quando se atreveu a escrever sobre a TV (Bourdieu, 1997). Este capitalismo fast e soft de hoje, usa em seu favor centros de investigação, laboratórios e bolseiros, como usa robots e gurus da administração. Faz lembrar o perturbador efeito da soft machine de William Burroughs (1961). Sob o signo da velocidade, está-se, hoje, a digitalizar os CVs e a sujeitá-los a uma métrica sinistra, condensada 
em algoritmos, fórmulas digitais e expeditos bar codes. Está-se também a substituir a leitura pela rápida "consulta". Exatamente como se está a substituir o livro pelo e-book, a conferência pela vídeo-conferência e as bibliotecas e os arquivos por simulacros de marca Google.

De que são feitas as sociedades, os mercados e os poderes quando os vemos? De verdade sociologicamente procurada e encontrada ou de pós-verdade ideologicamente urdida?

Quando se trata de assumir a responsabilidade pelas coisas que não dão bons resultados, a personalidade humana sempre se mostrou disponível para fabricar "outras verdades" (Campbell, 2011). Antes chamavam-se bodes expiatórios. Tenho a sensação de podermos estar, neste instante, a incorrer nesse mesmo estratagema e a apontar o dedo a Mr. Trump, ou Mr. Putin, ou a qualquer outro Mr. A, B, ou C.

Quem são os culpados pelo que se está a passar? Adão culpou a Eva e todos estamos dispostos, desde então, a culpar alguém pelos nossos atos falhados e que correram mal. Em vez disso, porque não perguntar à Sociologia e pesquisar com ela? Sobretudo à Sociologia que interroga sobre a origem do descalabro das coisas públicas, as mudanças nas sociedades, na estrutura dos mercados ou nas configurações dos poderes?

A abordagem sociológica original de uma tal interrogação pode situar-se no livro a Multidão Solitária de David Riesman (1961). Para Riesman, na era medieval, os objetivos de vida de cada um eram guiados pelos interiorizados valores da tradição. As coisas faziam-se como sempre se tinham feito e as crianças aprendiam a ser como os seus pais. O seu "falhanço" era motivo de profunda vergonha e a resposta encontrava-se nas regras da moral. Na era do consumo massificado, ainda para Riesman, os sujeitos são todos hetero-guiados e conduzidos por referências que lhes escapam. O "falhanço" pessoal resulta, agora, num perfeito american style, não da vergonha, mas do receio de não se ser/estar devidamente integrado no conjunto da sociedade. Surge assim uma ideia de "insucesso" e de culpa individual, atribuídos a quem não se comporta com as regras e valores coletivos. Inclusivamente, a pobreza foi, décadas a fio, sinal do desconcerto pessoal dos pobres.

Em anos mais próximos, a Sociologia beneficiou de uma outra reflexão sobre a expiação da culpa que, grosso modo, lê assim: o nosso pecado original reside na dificuldade em aceitar a responsabilidade pelas nossas próprias ações. Trata-se do argumento de Richard Sennett no seu notável A Corrosão do Caráter (Sennett, 2000). Depois de aludir às lutas de David contra Golias, para assinalar que um outro mundo é possível, e ao modo como o capitalismo tende a ser avaliado em função da carreira pessoal, Sennett sugere que o enunciado da culpa muda com a própria 
auto-avaliação e a discussão em grupo. Assim, depois da acusação de traição à IBM - o outsourcing decidido por Louis Gerstner, o então presidente judeu da empresa -, os informáticos descartados passaram a responsabilizar a insensibilidade dos jovens engenheiros indianos seus colegas, pagos a salários ínfimos. Estava encontrado o bode expiatório. Porém, quando a perfídia dos de fora foi posta em causa, os engenheiros desempregados da IBM "viraram-se para dentro", como escreve Sennett, e, ao mesmo tempo que procuravam restabelecer o sentido da sua integridade profissional, reconheciam dever-se à sua acomodação profissional e à sua débil relação com o mundo, as verdadeiras razões do seu "fracasso".

A ideia de responsabilidade pessoal e de brio profissional é, em grande parte, fruto do reconhecimento de que alguém precisa de nós. Hoje, todavia, a maior dificuldade reside em saber quem precisa realmente de nós. No capitalismo flexível, fast e soft, em que é difícil saber quem pode precisar de nós, a invenção dos bodes expiatórios instala-se com inegável frequência. O seu pior efeito é o de continuar a intensificar a desligação de cada um/a com o mundo. Mas com que mundo? O da pós-verdade e das fake news? Ou os mundos que a Sociologia nos convida a questionar?

O mundo que a Sociologia revela só se deixa perceber com mais e sempre mais Sociologia, como Ulrich Beck tanto gostava de repetir. Só mais e mais Sociologia nos pode assegurar, ou restituir, se for o caso, aquele sentimento de integridade pessoal, coletiva e planetária que os engenheiros informáticos de Sennett encontraram quando se "viraram para dentro" e passaram a pensar abertamente sobre o complexo mundo em que viviam, como se eles fossem os seus próprios "outros". Esta é uma Sociologia capaz de fazer de cada um/a um daqueles guardadores de rebanhos que, "deitados" sobre a realidade, ousam pensá-la com o corpo todo e, sem renunciar à busca da verdade, denunciam, ao vê-las, as manipulações lançadas sobre a sociedade, o mercado e o poder. Com esta sensível sociologia do rebanho, talvez possamos derrotar os efeitos da pós-verdade e, por certo também, do disfarce e da mentira. Restarão apenas as verdades dos factos e a vontade de sermos felizes com elas, como Alberto Caeiro suspeitava ser possível:

Sou um guardador de rebanhos.

O rebanho é os meus pensamentos

E os meus pensamentos são todos sensações.

Penso com os olhos e com os ouvidos

E com as mãos e os pés

E com o nariz e a boca. 
Sinto todo o meu corpo deitado na realidade,

Sei a verdade e sou feliz.

Alberto Caeiro, O Guardador de Rebanhos

\section{Notas}

Texto apresentado e discutido no X Congresso Português de Sociologia, realizado na Universidade da Beira Interior, Covilhã, entre 10 e 12 de Julho de 2018.

Por decisão pessoal, o autor do texto não escreve segundo as normas do novo acordo ortográfico.

\section{Referências}

Bourdieu, P. (1997). Sobre a televisão. Oeiras: Celta.

Burroughs, W. S. (1961). The soft machine. Paris: Olympia Press.

Campbell, C. (2011). Scapegoat: A history of blaming other people. Londres: Duckworth Overlook.

Kakutani, M. (2018). A morte da verdade. A falsidade na era de Trump. Lisboa: Editorial Presença.

Lopes, J. T. (2018, 4 de Junho). A “pós-verdade” e a sociologia. Público.

Riesman, D. (1961). The lonely crowd. New Haven: Yale University Press.

Sennett, R. (2000). A corrosão do caráter. As consequências pessoais do trabalho no novo capitalismo. Lisboa: Terramar.

Spivak, G. (2003). Death of a discipline. Nova Iorque: Columbia University Press.

Thrift, N. (2005). Knowing capitalism. Londres: Sage.

Data de submissão: 10/09/2018 | Data de aceitação: 13/12/2018 